\title{
Application of a Pheromone-Based Bees Algorithm for Simultaneous Optimisation of Key Component Sizes and Control Strategy for Hybrid Electric Vehicles
}

\section{Long VT*}

Research scholar from Nha Trang University, Faculty of Mechanical Engineering, Vietnam

\begin{abstract}
A Pheromone-Based Bees Algorithm (PBA) is employed to optimize the key component sizes and control strategy for parallel Hybrid Electric Vehicles (parallel HEVs) presented. The Basic Bees Algorithm (BBA) is an intelligent optimization tool mimicking the food foraging behavior of honey bees. In this research, however, a new version of BBA which uses pheromones, chemical substances secreted by bees and other insects into their environment, enabling them to communicate with other members of their own species, is applied. The PBA employs the pheromone to attract bees to explore the promising regions of the search space, and the parallel HEV configuration and an Electric Assist Control Strategy are used to formulate the research. The value of the key component size and control strategy parameters is adjusted according to PBA to obtain the minimization of weighted sum of Fuel Consumption (FC) and emissions while vehicle performance that satisfy the PNGV constraints. In this research, ADVISOR software has been used as the simulation tool, and driving cycles, FTP, ECE-EUDC and UDDS, are employed to evaluate FC, emissions and dynamic performances. Following a description of the algorithm, the paper shows the results obtained for the simultaneous optimization of key component sizes and control strategy for parallel Hybrid Electric Vehicles. The results prove that PBA is a strong algorithm for determining the optimal parameters of component sizes and control strategy resulting in improvement of $\mathrm{FC}$ and emissions without sacrificing vehicle performance. Compared to BBA, the new version, PBA, showed an improvement of about $25 \%$ in convergence speed with the nearly same results of optimization targets.
\end{abstract}

Keywords: Hybrid electric vehicles; Basic bees algorithm; Pheromone-based bees algorithm; Intelligent optimization; Parallel HEV control strategy

\section{Introduction}

Increasing concern about environmental issues, such as global warming and greenhouse gas emissions, as well as the predicted scarcity of oil supplies have made energy efficiency and reduced emissions a primary designing point for automobiles. HEVs have demonstrated improved fuel economy with lower emissions than conventional vehicles. Superior HEV performance in terms of higher fuel economy and lower emissions, with satisfaction of driving performance, necessitates a careful balance of key component sizes as well as control strategy parameter monitoring and tuning.

Optimal parameter value of component sizes and control strategy for HEVs have been studied previously [1-3]. The parametric optimization based on rule-based control was widely used in early studies whereas control concepts based on optimal theories such as Dynamic Programming (DP) or Pontryagin's Minimum Principle (PMP) [4,5] is more current. The optimal control parameters are obtained if the driving-cycle and vehicle performance such as fuel consumption, exhaust emission, and acceleration performance are known. In this case, the DP approach can find the global optimal solution [11-13]. However, DP has to use one more step, a post-processing step, such as neural networks to approximate the results of the optimal control pattern. Even then DP cannot cover all driving conditions. Hence, the real-time controller based on DP is effective only for the driving cycle that is used for rule extraction.

Another approach based on optimal control theory is PMP requiring less computing time than DP. While, control based on PMP can reduce the computational time for getting an optimal trajectory, it is a local optimal solution, not a global solution in general problems [7-
9]. In addition, some other approaches have used for the optimization of HEV. Asians (1996) tried to find optimal input variables including the sizes of ICE, EM and battery pack. The optimization objective was to improve the FC when the driving performances were kept within the standard limits. However, they did not account for the exhaust emissions [13]. Montazeri (2006) used Genetic Algorithm (GA) to find optimal component sizes and control strategy. Their objective was to minimize a weighted sum of FC and emissions while the PNGV (the Partnership for a New Generation of Vehicles) performance requirements were considered as constraints [6]. Wu used Particle Swarm Optimization to achieve optimal parameters for both the powertrain and control strategy, and vehicle performances were also defined as constraints. This research aimed to reduce FC, emissions, and manufacturing costs of HEVs. To solve this problem, they used a single objective problem with a goal-attainment method to replace the original multi-objective optimization problem.

In 2012, Long, used a basic Bees Algorithm to optimize parallel HEV component sizes and control strategy. The parameters include three parameters of component size and six parameters of control

*Corresponding author: Long VT, Research scholar from Nha Trang University, Faculty of Mechanical Engineering, Vietnam, Tel: + 8458-383-1149; E-mail: longvt ntu@yahoo.com

Received August 25, 2014; Accepted December 31, 2014; Published January 06, 2015

Citation: Long VT (2015) Application of a Pheromone-Based Bees Algorithm for Simultaneous Optimisation of Key Component Sizes and Control Strategy for Hybrid Electric Vehicles. Int J Swarm Intel Evol Comput 4: 113. doi: 10.4172/2090-4908.1000114

Copyright: (C) 2015 Long VT. This is an open-access article distributed under the terms of the Creative Commons Attribution License, which permits unrestricted use, distribution, and reproduction in any medium, provided the original author and source are credited. 
Citation: Long VT (2015) Application of a Pheromone-Based Bees Algorithm for Simultaneous Optimisation of Key Component Sizes and Control Strategy for Hybrid Electric Vehicles. Int J Swarm Intel Evol Comput 4: 113. doi:10.4172/2090-4908.1000114

Page 2 of 7

strategy. In this paper, the number of parameters of control strategy is expanded to seven [14]. In order to enhance convergence speed, the component size and control strategy parameters of parallel HEVs are optimized simultaneously by using the new version of Bees Algorithm, the Pheromone-Based Bees Algorithm, to obtain the minimization of weighted sum of FC and emissions when the PNGV driving performances such as acceleration and grad-ability of parallel HEVs are maintained.

\section{Parallel HEV component sizing and control strategy}

The parallel HEV component sizing: The parallel HEV configuration is shown in (Figure 1). In this configuration, both ICE and EM are mechanically connected to the driving wheels. The EM plays the role of assisting the ICE in supplying the required power. The ICE can also drive the EM as a generator to charge the battery [15-17]. In this research, the ICE, EM and battery are treated as key components in the design process of parallel HEVs.

HEV control strategy: There are some control strategies that are proposed for parallel HEVs. The Electric Assist Control Strategy (EACS) has been used in this research. Using EACS, the main energy provider is ICE and the EM is used as ICE assistance. The EACS is described in (Figures 2-4) [8] and [2].

The EACS can use the EM in a variety of ways [10]:

1. If the required speed is less than the electric launch speed (which is dependent on the SOC), the ICE could be turned off. In (Figure 4), above solid line the ICE is on and below solid line the vehicle attempts to run all electrically.

2. If the SOC is higher than its low limit, the ICE could be turned off. If the requested speed is less than the launch speed and the SOC is higher than the low limit, the ICE will be turned off.

3. If the required torque is less than a cutoff torque, cs_off_trq_ frac fraction of the maximum torque $\mathrm{T}_{\text {max }}$, the ICE could be turned off. If the requested torque is lower than this cutoff and the SOC is higher than the low limit, the ICE will be turned off.

4. When the battery SOC is below cs_lo_soc, additional torque is required from the ICE to charge the battery. This additional charging torque is proportional to the difference between SOC and the average of $c s$ lo_soc and cs_hi_soc. This ICE torque is prevented from being below a certain fraction, $c s \_m i n \_t r q \_f r a c$, of the maximum ICE torque $\mathrm{T}_{\text {max }}$ at the current operating speed. This is intended to prevent the ICE from operating at an inefficiently low torque.

Optimization targets: The HEV research objective is to minimize the weighted sum of FC and exhaust emissions ( $\mathrm{HC}, \mathrm{CO}$ and $\mathrm{NO}_{\mathrm{x}}$ ) while still satisfying charge sustaining requirement and driving performances. The PNGV passenger car constraints described in (Table 2) [19] are used as dynamic performance requirements to show that vehicle performance is not sacrificed during optimization.

The objective function is defined as follows:

$$
\mathrm{G}(\mathrm{x})=\mathrm{f}_{1} \mathrm{FC}+\mathrm{f}_{2} \mathrm{HC}+\mathrm{f}_{3} \mathrm{CO}+\mathrm{f}_{4} \mathrm{NO}_{\mathrm{x}}
$$

Where, $f_{1}$ to $f_{4}$ are also defined as weighting factors used to investigate the effect of different objectives on the optimization results.

\section{Bees algorithm for simultaneous optimization of component sizes and control strategy}

Bees Algorithm mimics the food foraging behavior of a swarm of honey bees. This algorithm performs a type of neighborhood search combined with random search.

Basic bees algorithm: The basic bee's algorithm is an intelligent optimization tool imitating the food foraging behavior of honey bees found in nature. In the natural environment bees are able to discover food sources using two kinds of search methods, namely, a global random search and a local search. The former consists of sending the bees at random around the hive. Once these bees, which are called the scout bees, discover potential food sources they return to their hive and start recruiting more bees to exploit those food sources which were discovered during the random search attempt. The bees waiting in the hive receive their instructions from the returning scout bees in the form of a waggle dance which gives them the following useful information: the location of the nearest food source, the quality of that food source, and the amount of energy needed to harvest the food. Logically, the better the food source and the closer to the hive the more numerous the recruited bees will be. The search performed by the recruited bees is similar to a local search. While some bees are recruited to conduct local search, a percentage of the bee population continues the global random search to look for other promising food sources. This ensures that the search continues cycle after cycle in an iterative manner until all the good food sources including the best food source in the vicinity of the hive are found. This is similar to an intelligent optimization process and can be formulated into an algorithmic form as in the basic Bees Algorithm [15].

Pheromone-based bees algorithm: In nature, the bees are known to secrete pheromones in a liquid form which is transmitted by coming into direct contact with it or as it is a vapor. The pheromones release chemical signals proportional to the amount which has been deposited by scout bees for marking potential food sources, marking their hive,
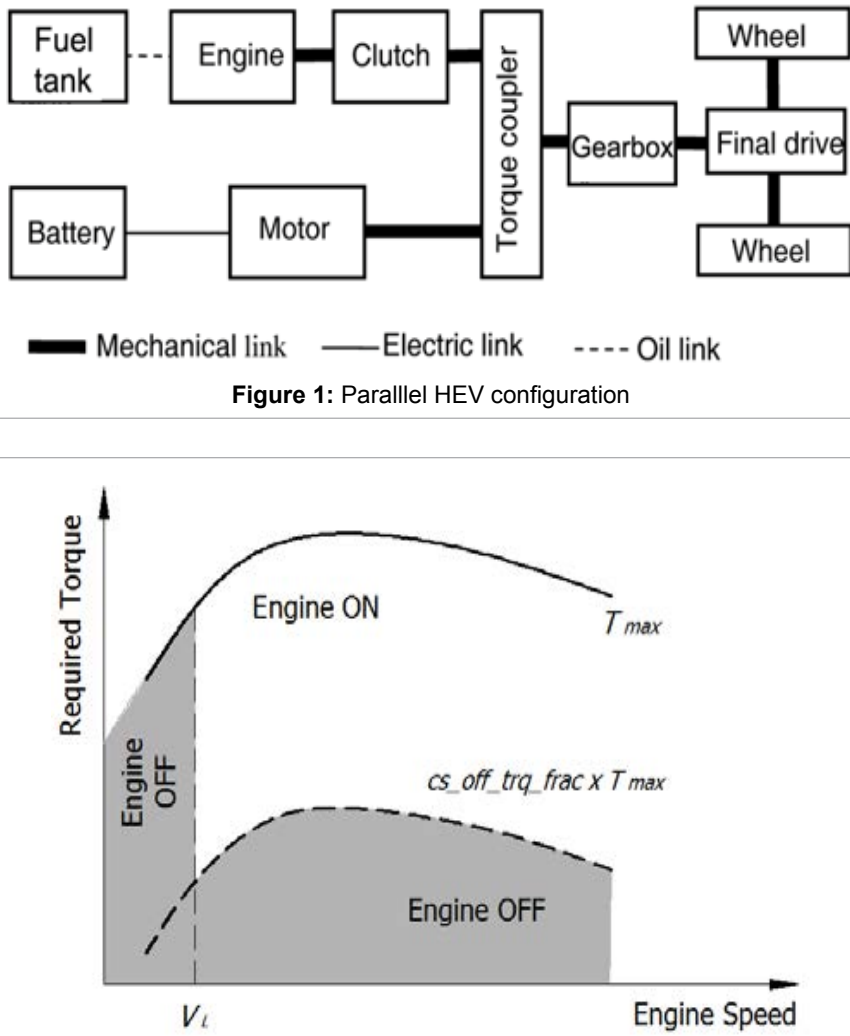

Figure 2: EACS, SOC > cs_lo_soc 


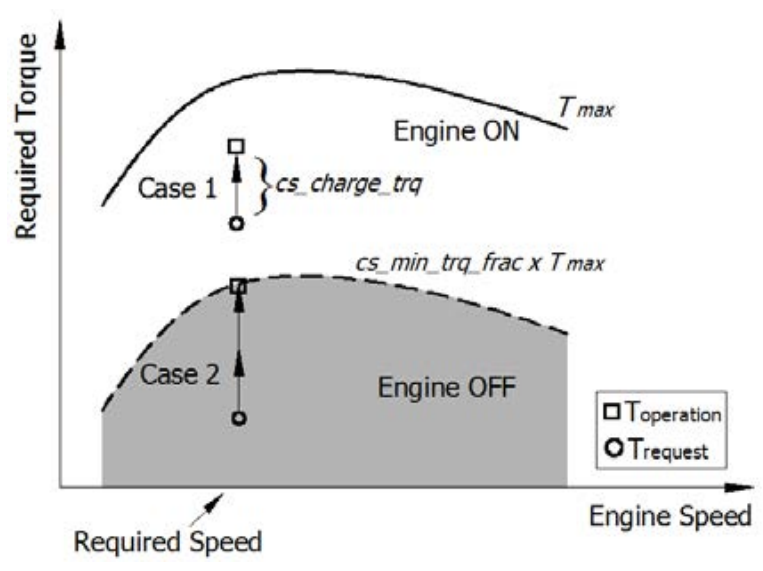

Figure 3: EACS, SOC < cs_lo_soc

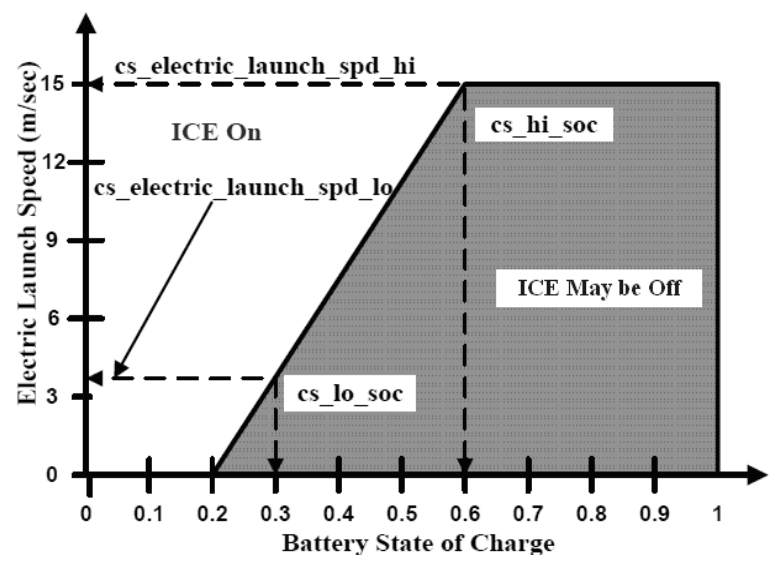

Figure 4: EACS, the electric launch speed logic

scenting potential hive sites, and assembling or recruiting other bees. The scent arising from the secreted pheromones can intensify or diminish over time depending on the level of bee activity at that site. A strong scent will help to recruit bees in larger numbers to the food source while a mild scent will indicate the depletion of nectar in a previously marked food source.

In the Pheromone-Based Bees Algorithm the number of scout bees allocated for global random search is defined by parameter " $n$ " and the number of bees assigned to search around the selected site "e" is defined by parameter " $\mathbf{m}$ ". In order to facilitate the search within a sphere centered on the selected sites, the parameter " $\mathbf{n}_{\mathrm{gh}}$ " is used to define the neighborhood size. In the Pheromone-Based Bees Algorithm, pheromones are used to recruit bees to search around each selected site. In every iteration, the bees deposit pheromones on the sites they are drawn to and the exact amount on a particular site depend on the quantity of pheromones already present on that site which is influenced by a decay rate, the fitness of that site, and the number of bees found on that site. The amount of pheromones found on a site will gradually evaporate to nothing, over time, if there is no bee activity there. Due to pheromone evaporation, the older the site, the less attractive it is (because it has been exploited and the nectar in it might have exhausted). As a consequence, the number of bees recruited to each site will be proportional to the quantity of pheromone already present on that site, and the fitness of that site. Thus the use of pheromones allows an automatic and dynamic recruitment of bees across the search space. The pheromones are used to recruit bees to a particular site, uses not only the quality of that site, i.e. fitness, but also the amount of pheromone found on the site. The precise amount of pheromone accumulated on each site will be calculated in each iteration using a pheromone update equation which will show either an increase or decrease in its level [15].

The Pheromone-Based Bees Algorithm is shown as in Figure 5, and its parameters are described in Table 3.

The algorithm starts with the initial population of $\mathrm{n}$ scout bees to search randomly in the solution space. Then, the fitness of the scout bees associated with their respective sites is evaluated in step 2. However, only bees with the highest fitness are chosen as "selected bees" and sites visited by them are selected for neighborhood search in step 3. After that, in steps 4, 5 and 6, the algorithm will search in the neighborhood of the selected sites, the number of bees " $m$ " recruited for each selected site depends on the pheromone deposited on that site. At the end of each neighborhood search, the bee having the highest fitness value associated with its visited patch is selected to form the next bee population

In order to avoid local optima, in step 7 , the remaining bees (n-e) in the population have to search randomly around the solution space to find new potential sites. The iteration of these above steps will not be finished until a stopping criterion is met and the best bee of the last population is treated as the optimal solution [21,22].

Pheromone-based bees algorithm in parallel HEV optimization: In order to apply PBA to the simultaneous optimization of parallel HEVs, the fitness in step 2 is the inverse of objective function $\mathrm{G}(\mathrm{x})$ in Equation (1). However, the optimization task is required to maintain the on road performances such as acceleration and grad-ability of parallel HEVs. Unfortunately, the PBA cannot work directly with constrained optimization problem. To solve this problem, it is necessary to add penalty functions into objective function $\mathrm{G}(\mathrm{x})$ [23].

$$
\begin{aligned}
& \operatorname{Min} \mathrm{G}(\mathrm{x}) \mathrm{x}=\left(\mathrm{x}_{1}, \mathrm{x}_{2}---\mathrm{x}_{10}\right) \\
& \text { Subject to } \mathrm{h}_{\mathrm{i}}(\mathrm{x}) \leq 0 \mathrm{i}=1,2, \ldots, 7 \\
& \left\{\begin{array}{l}
C_{1}(x)=\max \left(0, F_{1}(x)-\alpha_{1}\right) \\
C_{2}(x)=\max \left(0, F_{2}(x)-\alpha_{1}\right) \\
C_{3}(x)=\max \left(0, F_{3}(x)-\alpha_{1}\right) \\
C_{4}(x)=\max \left(0, \alpha_{4}-F_{4}(x)\right. \\
C_{5}(x)=\max \left(0, \alpha_{5}-F_{5}(x)\right. \\
C_{6}(x)=\max \left(0, \alpha_{6}-F_{6}(x)\right. \\
C_{7}(x)=\max \left(0, \alpha_{7}-F_{7}(x)\right. \\
\text { fitness }\left(S_{j}\right)_{(x)}=\frac{1}{G\left(S_{j}\right)_{(x)}+\sum_{i=1}^{7} k_{i} \times C_{i}\left(S_{j}\right)_{(x)}}
\end{array}\right.
\end{aligned}
$$

Where, $\mathrm{x}_{1}, \mathrm{x}_{2} \ldots \mathrm{x}_{10}$ are parameters of component sizes and control strategy listed in (Table 1)

$\mathrm{C}_{\mathrm{i}}\left(\mathrm{S}_{\mathrm{j}}\right)_{(\mathrm{x})}, \alpha_{\mathrm{i}}$ and $\mathrm{F}_{\mathrm{i}}(\mathrm{x})$ are penalty function, desired value and evaluated value related to $\mathrm{i}^{\text {th }}$ constrain $\mathrm{h}_{\mathrm{i}}(\mathrm{x})$ in (Table 2)

The penalty function is used to penalize infeasible solutions by reducing their fitness values. $\mathrm{C}_{\mathrm{i}}\left(\mathrm{S}_{\mathrm{j}}\right)_{(\mathrm{x})}=0$, if the constrain $\mathrm{h}_{\mathrm{i}}(\mathrm{x})$ is satisfied.

$\mathrm{k}_{\mathrm{i}}$ is penalty factor chosen by trial and error as given in (Table 2) 
Citation: Long VT (2015) Application of a Pheromone-Based Bees Algorithm for Simultaneous Optimisation of Key Component Sizes and Control Strategy for Hybrid Electric Vehicles. Int J Swarm Intel Evol Comput 4: 113. doi:10.4172/2090-4908.1000114

Page 4 of 7

\begin{tabular}{|c|c|}
\hline Parameters & Description \\
\hline fc_trq_scale & scaling factor for torque range of ICE \\
\hline mc_trq_scale & torque scaling factor of EM \\
\hline ess_module_num & number of battery modules in a pack \\
\hline cs_hi_soc & highest desired battery state of charge \\
\hline cs_lo_soc & lowest desired battery state of charge \\
\hline cs_electric_launch_spd_lo & Vehicle speed below which vehicle runs as pure electric vehicle (ZEV mode) at low battery SOC \\
\hline cs_electric_launch_spd_hi & Vehicle speed below which vehicle runs as pure electric vehicle (ZEV mode) at high battery SOC \\
\hline Cs_off_trq_frac & Cs_off_trq_frac $T_{\max }=$ minimum torque threshold; when commanded at a lower torque, the engine will shut off if SOC > cs_lo_soc \\
\hline cs_min_trq_frac & $\begin{array}{l}\text { cs_min_trq_frac }{ }^{*} T_{\text {max }}=\text { minimum torque threshold; when commanded at a lower torque, the engine will operate at the threshold torque } \\
\text { and the motor acts as a generator if the SOC }<\text { cs_lo_soc }\end{array}$ \\
\hline cs_charge_trq & $\begin{array}{l}\text { cs_charge_trq }((\text { cs_lo_soc }+ \text { cs_hi_soc }) / 2-S O C)=\text { an accessory like torque loading on the engine to recharge the battery pack } \\
\text { whenever the engine is on. }\end{array}$ \\
\hline
\end{tabular}

Table 1: Parameters of component size and EACS

\begin{tabular}{|c|c|c|}
\hline \multirow{2}{*}{ Parameterst } & Description & $\mathbf{k}_{\mathbf{i}}$ \\
\hline \multirow{2}{*}{ Acceleration time } & Time for $0-96.6 \mathrm{~km} / \mathrm{hr} \leq 12 \mathrm{~s}$ & 1.2 \\
\cline { 2 - 3 } & Time for $64.4-96.6 \mathrm{~km} / \mathrm{hr} \leq 5.3 \mathrm{~s}$ & 1.5 \\
\cline { 2 - 3 } & Time for $0-136.8 \mathrm{~km} / \mathrm{hr} \leq 23.4 \mathrm{~s}$ & 1.2 \\
\hline Gradeability & $\begin{array}{c}\text { \%.5 grade ability at } 88.5 \mathrm{~km} / \mathrm{hr}, 272 \mathrm{~kg} \\
\text { additional weight for } 20 \mathrm{~min}\end{array}$ & 2.0 \\
\hline Maximum speed & $\geq 137 \mathrm{~km} / \mathrm{hr}$ & 1.2 \\
\hline Maximum & $\geq 5 \mathrm{~m} / \mathrm{s}^{2}$ & 1.2 \\
\hline Distanceleration & $\geq 42.7 \mathrm{~m}$ & 1.2 \\
\hline
\end{tabular}

Table 2: PNGV performance constraints

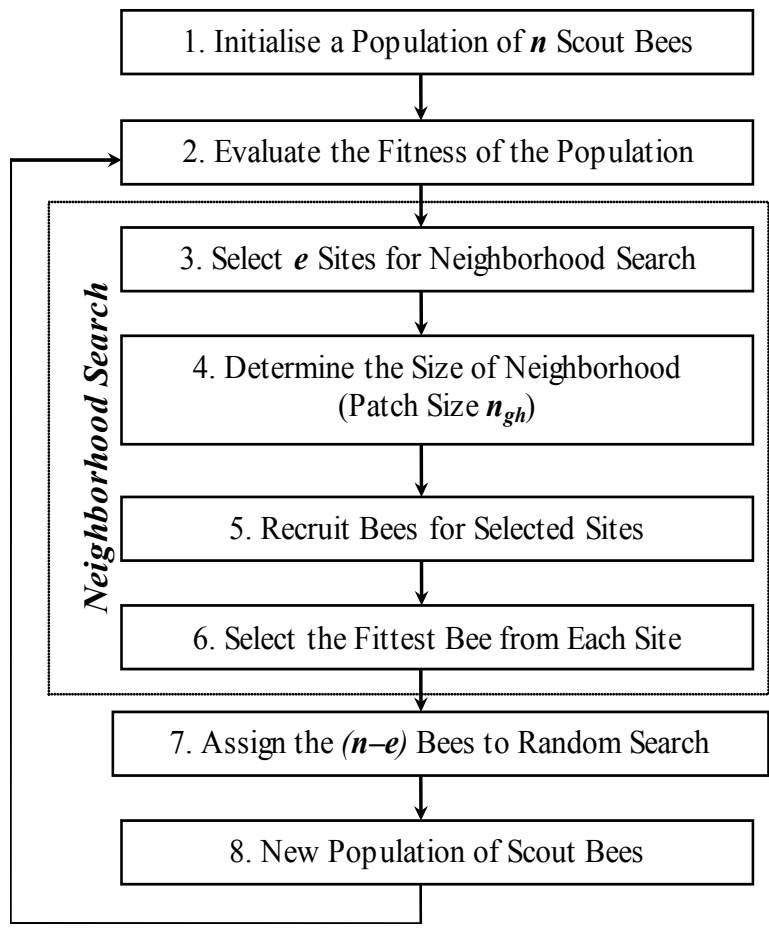

Figure 5: The flowchart of PBA

fitness $\left(S_{j}\right)_{(\mathrm{x})}$ is the fitness value of site $\mathrm{S}_{\mathrm{j}}$

The optimization process using PBA for parallel HEVs can be stated as follows:

Step 1: Initialize the population of scout bees, each scout is a set of specific values of all variables of component sizes and control strategy in (Table 1)
Step 2: Evaluate the FC, HC, $\mathrm{CO}, \mathrm{NO}_{\mathrm{x}}$ and penalty functions $\mathbf{C}_{\mathbf{i}}(\mathbf{x})$ for each scout bee by combining between PBA and ADVISOR software

Step 3: Calculate the fitness value of all scout bees according to Equation (3) and (4)

Step 4: Choose $\mathbf{e}$ bees with highest fitness

Step 5: Recruit bees for selected "e" sites according to the pheromone levels at those sites (local search) to conduct searches in the neighborhood of the selected e sites and choose a bee with the highest fitness for each site. The number of bees given by $n b\left(S_{j}, t\right)$ recruited for a site $S_{j}$ of $\mathbf{e}$ sites at time $t$ is calculated from Equation (5)

Step 6: Assign the remaining (n-e) bees to search randomly around the search space for new potential solutions

Step 7: At the end of the local and global search, the best bees from all the sites are sorted according to their fitness

Step 8: Update new population

Step 9: Update pheromone level on each site by using Equation (7)

Step 10: Stop the program if the convergence criteria is satisfied, otherwise go to step 4 .

$$
\begin{aligned}
& n_{b}\left(S_{j}, t\right)=\frac{p h\left(S_{j}, t-1\right)^{\alpha} \times f_{s}\left(S_{j}\right)^{\beta}}{\sum_{i=1}^{e}\left[p h\left(S_{i}, t-1\right)^{\alpha} \times f_{s}\left(S_{i}\right)^{\beta}\right]} \times \mathrm{m} \times \mathrm{e} \\
& f_{S}\left(S_{j}\right)=\frac{\operatorname{fitness}\left(S_{j}\right)-\operatorname{fitness}\left(S_{e+1}\right)}{\sum_{i=1}^{e}\left[\operatorname{fitness}\left(S_{i}\right)-\operatorname{fitness}\left(S_{e+1}\right)\right]} \\
& \operatorname{ph}\left(S_{j}, t\right)=p h\left(S_{j}, t-1\right) \times \rho+f_{s}\left(S_{j}\right) \times n_{b}\left(S_{j}, t\right)
\end{aligned}
$$

Where, $f_{S}\left(\mathrm{~S}_{\mathrm{j}}\right)$ is the fitness score of site $\mathrm{S}_{\mathrm{j}}$. $S_{e+1}$ are the best performing site among the non-selected sites. Note that the fitness score $f_{S}\left(S_{j}\right)$ is normalized to smooth noise and suppress systematic variations. The optimization process is programmed and linked with ADVISOR by using *.m file in Matlab [7]. The linkage configuration between ADVISOR and PBA is described in (Figure 6). The parameters of PBA used in this optimization are chosen as in (Table 4)

Where, up. Bound ${ }_{(i)}$ and lo. Bound ${ }_{(i)}$ are the upper bound and lower bound of variable $\mathrm{i}^{\text {th }}$ listed in (Table 6)

ADVISOR software gives different component modules such as fuel converter, energy storage, motor, etc. to build a vehicle system. In 
Citation: Long VT (2015) Application of a Pheromone-Based Bees Algorithm for Simultaneous Optimisation of Key Component Sizes and Control Strategy for Hybrid Electric Vehicles. Int J Swarm Intel Evol Comput 4: 113. doi:10.4172/2090-4908.1000114

Page 5 of 7

\begin{tabular}{|c|l|}
\hline Parameters & \multicolumn{1}{|c|}{ Description } \\
\hline $\mathrm{n}$ & number of scout bees \\
\hline $\mathrm{e}$ & number of sites selected out of $\mathrm{n}$ visited sites \\
\hline $\mathrm{m}$ & number of bees recruited for selected e sites \\
\hline $\mathrm{n}_{\mathrm{gh}}$ & size of patches, which includes site and its neighborhood \\
\hline & Table 3: The parameters of PBA \\
\hline
\end{tabular}

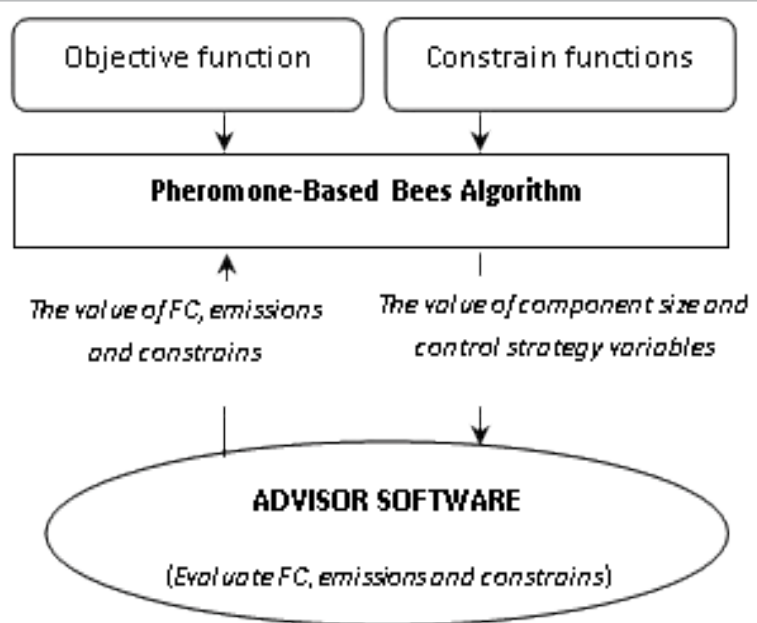

Figure 6: The combination between ADVISOR and Pheromone-Based Bees Algorithm

\begin{tabular}{|c|c|c|c|}
\hline $\mathrm{n}$ & $\mathrm{e}$ & $\mathrm{m}$ & $\mathrm{n}_{\text {gh(i) }}$ \\
\hline 23 & 7 & 5 & (up. bound $(i)$-lo. Bound $_{(i)}$ )/40 \\
\hline \multicolumn{4}{|c|}{ Table 4: The parameters of PBA } \\
\hline
\end{tabular}

order to continuously adjust component sizes in the search space, the fixed parameters are used for the simulation of the parallel HEV shown in (Table 5). To vary component size, the baseline ICE of Geo Metro 1.0L SI engine is used. The engine torque scale factor, $f c_{-} t r q_{-} s c a l e$, is also used to vary the ICE size. In addition, for the baseline electric motor, a Westinghouse AC induction motor is employed. The same as ICE, the motor torque scale factor, $m c \_t r q \_s c a l e$, is used to vary the EM size. Similarly, the Hawker Genesis Valve-Regulated Lead-Acid (VRLA) battery is used for battery sizing. To vary the battery size, the number of battery modules, ess_module_num, is changed [8].

The range of component size and control strategy variables is given in (Table 6).

Simulation results and analysis: In order to eliminate the influence of energy from the battery on fuel consumption, the simulation has been run several times starting with different initial SOC values until the final SOC is close to the initial SOC. After running the optimization program with PBA parameters in (Table 4) following three driving cycles, FTP, ECE-EUDC and UDDS. The optimal parameters, FC, emissions and dynamic performances, are shown in (Tables 7-9).

The results in the above tables prove the power of the PBA. With the optimal parameters of component sizes and control strategy listed in (Table 7), the FC, HC, CO and NOx are improved and dynamic performances are satisfied the PNGV constrains. The FC, emissions and vehicle performances obtained by using PBA with the driving cycles FTP, ECE-EUDC and UDDS are nearly same as ones employed by BBA. However, the rate of convergence of PBA is faster than that optimized by BBA $[13,14]$. The optimization process in this research will be stopped after 30 iterations or when the value of objective function does not reduce after 15 iterations. The set of component size and control strategy variables of the last best bee at the last iteration is considered as the best solution for optimization of the parallel HEVs. Compared to the BBA, the new version, PBA, showed an improvement of about $25 \%$ in convergence speed. This indicates the good performance of the PBA approach in saving time to achieve the optimal parameters.

\section{Conclusions}

The paper presents a simultaneous optimization of parallel HEV component sizes and control strategy to minimize the weighted sum of FC and emissions without sacrificing road performance by using a new approach, Pheromone-Based Bees Algorithm. Similar to the BBA, the PBA employs a type of neighborhood search (local search) combined with a random search (global search) in the solution space, so the results of component size and control strategy parameters of parallel HEVs are ensured to be global solutions. However, as the PBA employs pheromones to attract bees to explore promising regions of the search space, it can find the best solution approximately $25 \%$ faster than the basic Bees Algorithm. The results show that, the PBA approach is powerful in searching the best parameters of parallel HEVs in the solution space resulting in improvement of FC and reduction of $\mathrm{HC}, \mathrm{CO}$ and NOx, while PNGV constrains are maintained.

\begin{tabular}{|l|l|}
\hline \multicolumn{1}{|c|}{ Parameters } & \multicolumn{1}{c|}{ Description } \\
\hline ICE & $\begin{array}{l}\text { Geo Metro 1.0L SI engine with the maximum } \\
\text { power output of } 41 \mathrm{~kW} \text { and peak efficiency of } \\
0.34\end{array}$ \\
\hline EM & $\begin{array}{l}\text { Westinghouse AC induction motor with a } \\
\text { maximum power output of } 75 \mathrm{~kW} \text { and peak } \\
\text { efficiency of } 0.92\end{array}$ \\
\hline Battery pack & Lead-Acid (VRLA), 12V26Ah \\
\hline Body mass & $592 \mathrm{~kg}$ \\
\hline Rolling resistance coefficient & 0.009 \\
\hline Body aerodynamic \\
drag coefficient & 0.335 \\
\hline Vehicle front area & $2 \mathrm{~m}{ }^{2}$ \\
\hline Wheel radius & $0.282 \mathrm{~m}$ \\
\hline Gearbox Gear ratio: & $2.84,3.77$ \\
\hline Efficiency: & $5.01,5.57$ and 13.45 \\
\hline Catalyst converter & $95 \%$ \\
\hline Cargo mass & $\begin{array}{l}\text { close-coupled conventional converter for an } \\
\text { SI engine }\end{array}$ \\
\hline & $136 \mathrm{~kg}$. \\
\hline
\end{tabular}

Table 5: The fixed parameters of parallel HEVs

\begin{tabular}{|c|c|c|}
\hline Parameters & Lower bound & Upper bound \\
\hline fc_trq_scale & 0.5 & 1.5 \\
\hline mc_trq_scale & 0.1 & 1.2 \\
\hline ess_module_num & 7 & 30 \\
\hline cs_electric_launch_spd_lo (m/s) & 0 & 10 \\
\hline cs_electric_launch_spd_hi (m/s) & 11 & 35 \\
\hline cs_min_trq_frac & 0.1 & 0.8 \\
\hline cs_off_trq_frac & 0 & 0.2 \\
\hline cs_lo_soc & 0.15 & 0.57 \\
\hline cs_hi_soc & 0.58 & 0.95 \\
\hline cs_charge_trq (N.m) & 5 & 40 \\
\hline
\end{tabular}

Table 6: The range of variables 
Citation: Long VT (2015) Application of a Pheromone-Based Bees Algorithm for Simultaneous Optimisation of Key Component Sizes and Control Strategy for Hybrid Electric Vehicles. Int J Swarm Intel Evol Comput 4: 113. doi:10.4172/2090-4908.1000114
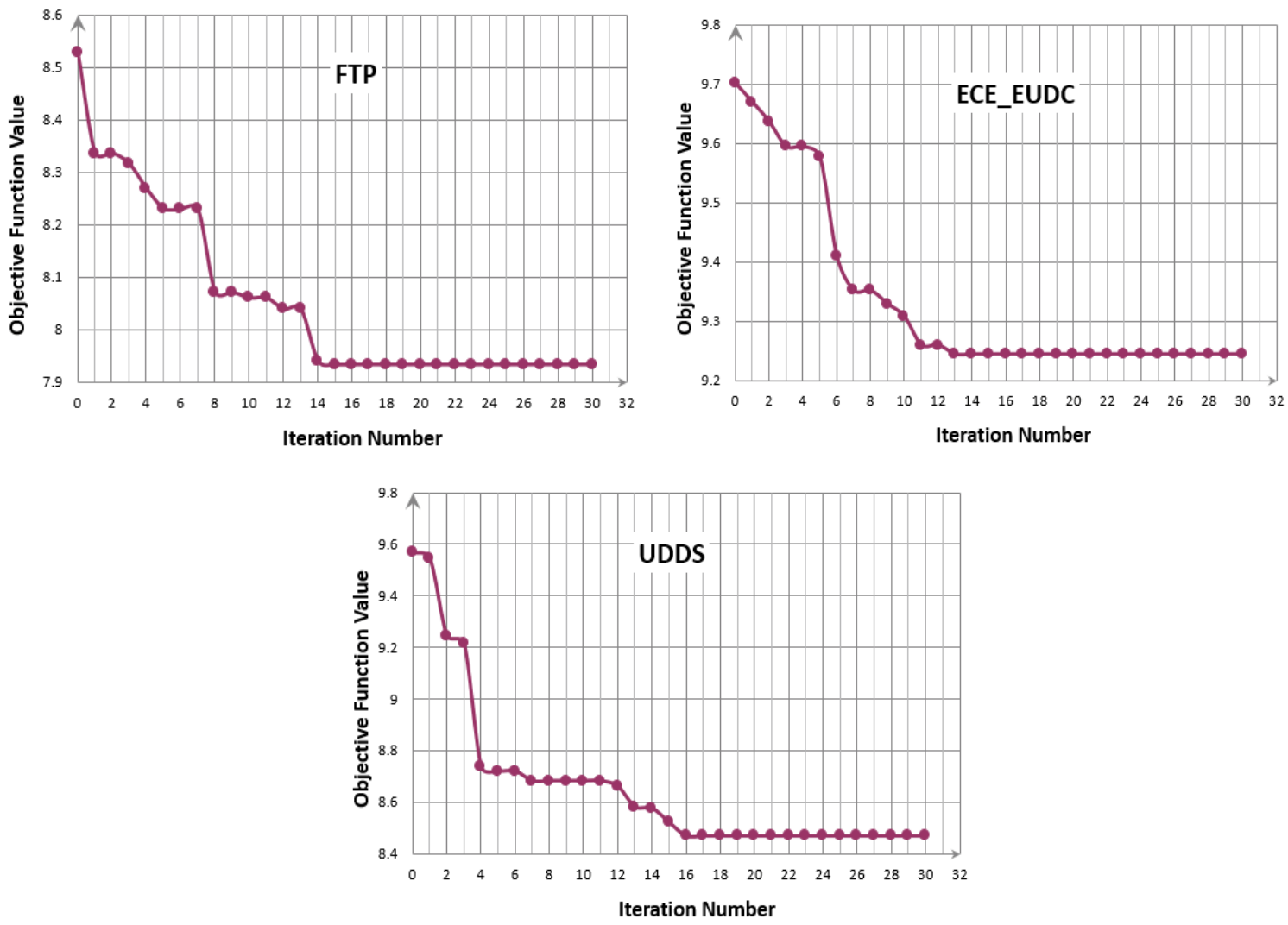

Figure 7: Optimization process for three driving cycles

\begin{tabular}{|l|c|c|c|}
\hline \multicolumn{1}{|c|}{ Parameters } & FTP & ECE-EUDC & UDDS \\
\hline fc_trq_scale & 1.090 & 1.010 & 1.061 \\
\hline mc_trq_scale & 0.165 & 0.181 & 0.162 \\
\hline ess_module_num & 12.895 & 14.253 & 13.028 \\
\hline cs_electric_launch_spd_lo (m/s) & 0.375 & 4.294 & 0.232 \\
\hline cs_electric_launch_spd_hi (m/s) & 29.609 & 13.828 & 30.506 \\
\hline cs_min_trq_frac & 0.109 & 0.346 & 0.122 \\
\hline cs_off_trq_frac & 0.146 & 0.021 & 0.150 \\
\hline cs_lo_soc & 0.537 & 0.459 & 0.542 \\
\hline cs_hi_soc & 0.719 & 0.800 & 0.726 \\
\hline cs_charge_trq (N.m) & 6.526 & 23.569 & 8.971 \\
\hline
\end{tabular}

Table 7: The value of optimal parameters

\begin{tabular}{|c|c|c|c|}
\hline Parameters & FTP & ECE-EUDC & UDDS \\
\hline FC (liter $/ 100 k m)$ & 5.3 & 5.9 & 5.4 \\
\hline $\mathrm{HC}(\mathrm{g} / \mathrm{km})$ & 0.291 & 0.39 & 0.37 \\
\hline $\mathrm{CO}(\mathrm{g} / \mathrm{km})$ & 1.234 & 1.76 & 1.60 \\
\hline $\mathrm{NO}_{\mathrm{x}}(\mathrm{g} / \mathrm{km})$ & 0.244 & 0.27 & 0.29 \\
\hline
\end{tabular}

Table 8: FC and emissions

\begin{tabular}{|c|c|c|c|}
\hline Parameters & FTP & ECE-EUDC & UDDS \\
\hline Grade & 7.4 & 7.0 & 7.2 \\
\hline$(0-97) \mathrm{km} / \mathrm{h} \mathrm{(s)}$ & 10.4 & 10.5 & 10.5 \\
\hline$(64-97) \mathrm{km} / \mathrm{h} \mathrm{(s)}$ & 5.3 & 5.3 & 5.3 \\
\hline$(0-137) \mathrm{km} / \mathrm{h}(\mathrm{s})$ & 21.9 & 22.2 & 22.0 \\
\hline Max. speed (m/s) & 176.6 & 174.9 & 175.7 \\
\hline Max. acc $\left(\mathrm{m} / \mathrm{s}^{2}\right)$ & 5.0 & 5.0 & 5.0 \\
\hline Dist. In 5 sec. $(\mathrm{m})$ & 50.8 & 50.8 & 50.6 \\
\hline
\end{tabular}

\section{References}

1. Assanis D, Delagrammatikas G, Fellini R, Filipi Z, Liedtke J, et al. (1996) An optimization approach to hybrid electric propulsion system design.

2. Chirag D (2010) Design and optimization of hybrid electric vehicle drivetrain and control strategy parameters using evolutionary algorithms. A Thesis in The Department of Electrical and Computer engineering, Concordia University Canada.

3. Han Z, Yuan Z, Guangyu T, Quanshi C, Yaobin C, et al. (2004) Optimal Energy Management Strategy for Hybrid Electric Vehicles. SAE Paper 1: 576.

4. Karaboga D, Akay B (2009) A comparative study of Artificial Bee Colony algorithm. Applied Mathematics and Computation 214: 108-132.

5. Kim N, Cha S, Peng H (2011) Optimal Control of Hybrid Electric Vehicles Based on Pontryagin's Minimum Principle. IEEE Trans Control System Technology 19: $1279-1287$.

6. Moore TC, Lovins AB (1995) Vehicle Design Strategy to Meet and Exceed PNGV Goals. SAE 95-27.

7. Markel T, Brooker A, Hendricks T, Johnson V, Kelly K, et al. (2002) Advisor: a systems analysis tool for advanced vehicle modelling. Journal of Power Sources 110: 255-266.

8. Montazeri-Gh, M, Poursamad A (2006) Appliacation of Genetic Algorithm for Simultaneous Optimization of HEV Component Sizing and Control Strategy. Int. J. Alternative Propulsion 1: 63-78.

9. Namwook K, Sukwon C, Huei P (2011) Optimal Control of Hybrid Electric Vehicles Based on Pontryagin's Minimum Principle. Control Systems Technology IEEE Transactions on 19: 1279-1287.

10. National Renewable Energy Laboratory (2001) Documentation ADVISOR software 3.2.

11. Lin CC, Peng H, Grizzle JW, Kang J (2003) Power Management Strategy for a Parallel hybrid Electric Truck. IEEE Trans Control Syst. technol 11: 839-849.

12. Liu J, Peng H (2006) Control Optimization for a Power-Split Hybrid Vehicle. American Control Conf Minneapolis Minnesota 466-471.

13. Long VT, Nhan NV (2012) Bees-algorithm-based optimization of component 
Citation: Long VT (2015) Application of a Pheromone-Based Bees Algorithm for Simultaneous Optimisation of Key Component Sizes and Control Strategy for Hybrid Electric Vehicles. Int J Swarm Intel Evol Comput 4: 113. doi:10.4172/2090-4908.1000114

size and control strategy parameters for parallel hybrid electric vehicles. International Journal of Automotive Technology 13: 1177 - 1183.

14. Long VT (2012) Application of Bees Algorithm for simultaneous optimisation of HEV key component sizes and control strategy. The 2nd international conference on automotive technology, engine and alternative fuels 6 : 37-43.

15. Packianather MS, Landy M, Pham DT (2009) Enhancing the speed of the Bees Algorithm using Pheromone-based Recruitment. 7th IEEE International Conference on Industrial Informatics 789-794.

16. Pham DT, Ghanbarzadeh A, Koc E, Otri S, Rahim S, et al. (2005) The Bees Algorithm Technical Note Manufacturing Engineering Centre. Cardiff University UK.

17. Pham DT, Ghanbarzadeh A, Koc E, Otri S, Rahim S, et al. (2006) The Bees Algorithm - A Novel Tool for Complex Optimisation Problems. Proceedings of IPROMS Conference 454-461.
18. Pu JH, Yin CL, Zhang JW (2005) Fuzzy torque control strategy for parallel hybrid electronic vehicles. Int. J. Automotive Technology 6: 529-536.

19. Srdjan ML, Ali E (2004) Effects of Drivetrain Hybridization on Fuel Economy and Dynamic Performance of Parallel Hybrid Electric Vehicles. IEEE Transaction on Vehicular Technology 53: 385-389.

20. Suh B, Frank A, Chung YJ, Lee EY, Chang YH, et al. (2011) Powertrain System Optimization for A Heavy-duty Hybrid Electric Bus. Int. J. Automotive Technology 12: 131-139.

21. Vadim F (1996) Global Methods in optimal control theory. Marcel Dekker Inc 140.

22. Wu J, Zhang CH, Cui NX (2008) Pso Algorithm-Based Parameter Optimization for HEV Powertrain and Its Control Strategy. Int. J. Automotive Technology 9 : 53-69.

23. Yeniay O (2005) Penalty Function Methods for Constrained Optimization with Genetic Algorithms. Math and Comp. Applications 10: 45-56.
Citation: Long VT (2015) Application of a Pheromone-Based Bees Algorithm for Simultaneous Optimisation of Key Component Sizes and Control Strategy for Hybrid Electric Vehicles. Int J Swarm Intel Evol Comput 4: 113. doi: 10.4172/2090-4908.1000114 